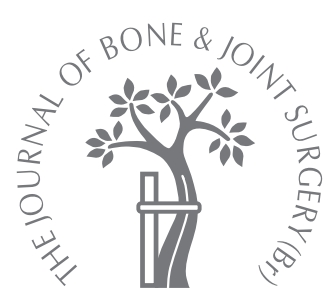

\title{
Percutaneous screw fixation versus conservative treatment for fractures of the waist of the scaphoid
}

\author{
A PROSPECTIVE RANDOMISED STUDY
}

M. M. McQueen, M. K. Gelbke, A. Wakefield, E. M. Will, C. Gaebler

From the Edinburgh Orthopaedic Trauma Unit, Edinburgh, Scotland

= M. M. McQueen, MD, FRCSEd(Orth), Consultant Orthopaedic Trauma Surgeon I E. M. Will, MCSP, Research Physiotherapist

Edinburgh Orthopaedic Trauma Unit

Royal Infirmary of Edinburgh, Old Dalkeith Road, Edinburgh EH16 4SU, UK.

M. K. Gelbke, MD Orthopaedic Surgery Resident Department of Orthopaedic Surgery

University of Michigan, $1500 \mathrm{E}$ Medical Center Drive, 2912D Taubman Center, Ann Arbor, Michigan 48109, USA.

A. Wakefield, MSc, MCSP, Research Physiotherapist Trauma and Orthopaedics F Level MP 45

Southampton General

Hospital, Tremona Road,

Southampton SI6 6YD, UK.

a C. Gaebler, MD, PhD,

Professor

Facharzt für Unfallchirurgie und Sporttraumatologie

Medizinische Universität Wien

University Klinik für

Unfallchirurgie Währinger

Gürtel 18-20, A-1090 Wien,

Austria.

Correspondence should be sent to Miss M. M. McQueen; e-mail: mmcqueen@staffmail.ed.ac.uk

(C)2008 British Editorial Society of Bone and Joint Surgery doi:10.1302/0301-620X.90B1. $19767 \$ 2.00$

$J$ Bone Joint Surg $[B r]$ 2008;90-B:66-71.

Received 31 May 2007:

Accepted 31 July 2007

\begin{abstract}
We randomly allocated 60 consecutive patients with fractures of the waist of the scaphoid to percutaneous fixation with a cannulated Acutrak screw or immobilisation in a cast. The range of movement, the grip and pinch strength, the modified Green/O'Brien functional score, return to work and sports, and radiological evidence of union were evaluated at each follow-up visit. Patients were followed sequentially for one year.

Those undergoing percutaneous screw fixation showed a quicker time to union $(9.2$ weeks vs 13.9 weeks, $p<0.001$ ) than those treated with a cast. There was a trend towards a higher rate of nonunion in the non-operative group, although this was not statistically significant. Patients treated by operation had a more rapid return of function and to sport and full work compared with those managed conservatively. There was a very low complication rate.

We recommend that all active patients should be offered percutaneous stabilisation for fractures of the waist of the scaphoid.
\end{abstract}

Although one of the smallest bones in the body, the carpal scaphoid is the subject of hundreds of publications, dozens of review articles and several books. More than $80 \%$ of carpal fractures involve the scaphoid, with the majority occurring in young men following simple falls or sports injuries ${ }^{1}$. There can be substantial morbidity, time off work and loss of earnings. Depending on the location and severity of the fracture, prolonged immobilisation in a cast may be required. Despite much attention by the orthopaedic community, treatment of fractures of the carpal scaphoid is not without challenge and there are a number of unanswered questions.

Many clinical studies have evaluated the treatment of fractures of the scaphoid. ${ }^{2-7}$ However, interpretation of the data can be difficult, as most studies do not distinguish between nondisplaced fractures and those most likely to have healing problems. There are fundamental differences between displaced and undisplaced fractures with regard to the risks of nonunion, malunion, and osteonecrosis. Displaced fractures have been associated with rates of nonunion and osteonecrosis in excess of $50 \%{ }^{5,6}$ Most authors recommend operative fixation for displaced fractures of the proximal pole and for those where diagnosis and treatment are delayed. ${ }^{1,5}$ Long-term follow-up studies have shown that malunited fractures and especially nonunions can lead to radiocarpal and midcarpal arthrosis, as well as carpal malalignment., ${ }^{2,-12}$ These changes may cause pain, weakness and stiffness. Cadaver studies have demonstrated that deformity of the scaphoid leads to loss of movement, particularly extension. ${ }^{13}$

Nondisplaced fractures of the waist of the scaphoid treated with cast immobilisation will usually heal in good alignment., ${ }^{3,7}$ Although there has been considerable debate about the type of cast used, there is little evidence for the use of long-arm casts and the tradition of including the thumb has not been shown to be beneficial. $^{14,15}$

Immobilisation is usually required for 8 to 12 weeks but may be longer in patients with delayed union. The functional consequences of this prolonged immobilisation are poorly reported, but significant joint stiffness and muscle wasting can occur. ${ }^{16,17}$

Open reduction and internal fixation of acute scaphoid fractures has been reported to give good results in several nonrandomised, retrospective studies. ${ }^{16,18-21}$ The incidence of complications after operative treatment of nondisplaced fractures has decreased with the advent of safer, more reliable implants and percutaneous techniques. Haddad and Goddard ${ }^{22}$ reported union rates approaching $100 \%$, excellent functional results, rare complications and return to manual labour within five weeks after percutaneous fix- 
Table I. Demographics of the patient population

\begin{tabular}{|c|c|c|c|}
\hline & All patients & Operative & Non-operative \\
\hline Mean age in yrs (range) & 29.4 (17 to 65$)$ & 28.3 (17 to 55$)$ & 30.5 (19 to 65$)$ \\
\hline \multicolumn{4}{|l|}{ Gender } \\
\hline Male & 50 & 26 & 24 \\
\hline Female & 10 & 4 & 6 \\
\hline \multicolumn{4}{|l|}{ Employment } \\
\hline Sedentary & 19 & 12 & 7 \\
\hline Light manual & 14 & 8 & 6 \\
\hline Moderate manual & 13 & 2 & 11 \\
\hline Heavy manual & 9 & 5 & 4 \\
\hline Retired/unemployed & 5 & 3 & 2 \\
\hline \multicolumn{4}{|l|}{ Mode of injury } \\
\hline Fall & 18 & 7 & 11 \\
\hline Fall from height & 9 & 5 & 4 \\
\hline Direct blow & 7 & 2 & 5 \\
\hline Sport & 18 & 10 & 8 \\
\hline Motorcycle driver & 6 & 4 & 2 \\
\hline Pedestrian & 1 & 1 & 0 \\
\hline Other & 1 & 1 & 0 \\
\hline \multicolumn{4}{|l|}{ Side of injury } \\
\hline Left & 34 & 14 & 20 \\
\hline Right & 26 & 16 & 10 \\
\hline
\end{tabular}

ation and immediate post-operative mobilisation. In a prospective randomised trial of 25 full-time military personnel with acute nondisplaced fractures of the waist of the scaphoid, faster radiological union and return to military duty was reported after percutaneous cannulated screw fixation compared with cast immobilisation. ${ }^{23}$ A cost/utility analysis of open reduction and internal fixation versus cast immobilisation for acute nondisplaced fractures of the midwaist of the scaphoid suggested that the former is cost saving from the social perspective. ${ }^{24}$ Furthermore, when considering only direct costs, open reduction and internal fixation was shown to be cost-effective compared with other widelyaccepted interventions.

The purpose of this study was to further investigate the outcome and functional results of percutaneous screw fixation compared with cast immobilisation of fractures of the waist of the scaphoid.

\section{Patients and Methods}

A prospective randomised trial was performed on 60 patients between the ages of 17 and 65 years who presented to one of two orthopaedic trauma units (Edinburgh, Vienna) with a Herbert type B1 or B2 ${ }^{16}$ fracture of the scaphoid (Table I). There were 50 males and 10 females with a mean age of 29.4 years (17 to 65 ). The mean age was 27 years (17 to 65 ) for the men and 40 (21 to 64$)$ for the women. A total of 25 patients had fractured their dominant side and only one patient, allocated to the operative group, had a B1 fracture. All but seven fractures were undisplaced.
Patients were excluded if they had a previous ipsilateral fracture of the scaphoid, additional injuries to the ipsilateral upper extremity, a pathological condition of bone, a terminal disease, evidence of substance abuse, polytrauma or were unwilling or unable to co-operate with follow up.

Patients were randomised into two groups using closed opaque envelopes. Group 1 underwent percutaneous fixation of the scaphoid within 14 days of injury using a standard Acutrak screw (Acumed, Alton, United Kingdom). Group 2 were treated in a Colles cast with the thumb

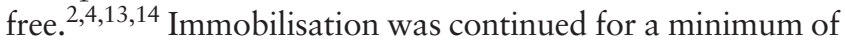
eight weeks. If clinical or radiological examination suggested delayed union, a further cast was applied. No patient was treated in a cast for longer than 12 weeks, irrespective of the clinical or radiological findings.

The operative technique was the same in both centres. Under tourniquet and with the patient supine, the upper limb was positioned on a hand table with the forearm supinated and the wrist extended over a roll. Reduction of the fracture was confirmed fluoroscopically. A guide wire was inserted percutaneously onto the tubercle of the scaphoid and the correct entry point confirmed radiologically. The guide wire was introduced into the scaphoid using a power drill, taking care to place it centrally with its tip at the proximal pole. A satisfactory position was confirmed using anteroposterior (AP), lateral, pronated and supinated oblique views of the wrist. The tip of a second guide wire was placed at the entry point and the difference in length between the wires was measured. 
Table II. The results of functional testing for the two groups at each review

\begin{tabular}{lcccc}
\hline & Review time (wks) & Operative & Non-operative & p-value $^{*}$ \\
\hline Mean decrease grip strength (\%) & 8 & $10(-35$ to 72$)$ & $42(3$ to 89$)$ & $<0.001$ \\
& 12 & $3(-11$ to 27$)$ & $25(-1$ to 80$)$ & $<0.001$ \\
& 26 & $-1(-13$ to 11$)$ & $11(-10$ to 96$)$ & $<0.001$ \\
& 52 & $-2(-12$ to 14$)$ & $5(-21$ to 81$)$ & 0.30 \\
Mean decrease pinch strength (\%) & 8 & & & \\
& 12 & $9(-6$ to 58$)$ & $29(-11$ to 81$)$ & $<0.001$ \\
& 26 & $4(-20$ to 39$)$ & $15(-31$ to 71$)$ & 0.012 \\
Mean decrease range of movement (\%) & 8 & $0(-21$ to 40$)$ & $3(-30$ to 85$)$ & 0.78 \\
& 52 & $-5(-27$ to 17$)$ & $1(-27$ to 82$)$ & 0.49 \\
& 12 & & & \\
& 26 & $11(-6$ to 64$)$ & $52(12$ to 79$)$ & $<0.001$ \\
& 52 & $6(-7$ to 30$)$ & $32(0$ to 88$)$ & $<0.001$ \\
& & $3(-14$ to 22$)$ & $11(-3$ to 73$)$ & 0.018 \\
\hline
\end{tabular}

* Mann-Whitney U test

Approximately $2 \mathrm{~mm}$ was subtracted from this value to obtain the desired screw length. The guide wire was then advanced into the radius to prevent it backing out with drill extraction. A $2 \mathrm{~mm}$ incision was made where the wire entered the skin. The scaphoid was drilled to the measured length under fluoroscopic control using a tapered cannulated Acutrak drill. A standard-sized Acutrak screw was inserted and its position confirmed fluoroscopically. One suture was placed in the wound. The wrist was not immobilised and patients were encouraged to mobilise within the limits of comfort. Physiotherapy was prescribed if clinically indicated. Clinical and radiological review were carried out at 8, 12, 26 and 52 weeks when tenderness at the fracture site and any complications were recorded.

Four standard views were taken at each visit (AP, lateral, $45^{\circ}$ and $135^{\circ}$ obliques), as described by Ziter. ${ }^{25}$ Union was assessed by the two senior authors (MMM, CG) and considered to have occurred when there was no tenderness at the fracture site and evidence of trabeculae crossing it on at least three views. Nonunion was defined as absence of trabeculae crossing the fracture site with a persistent fracture gap and tenderness at 16 weeks. ${ }^{26,27}$ Malalignment was defined as the presence of a dorsal intercalated segment instability deformity. ${ }^{13}$ Resorption was defined as an increasing fracture gap.

A research physiotherapist in each centre, blinded to the treatment method by sticking plaster over the entry position, undertook functional testing at $8,12,26$ and 52 weeks after fracture. This included range of movement (ROM), grip and pinch strength, time to return to work, sport and normal activities of daily living (ADL), and a modified functional assessment. ${ }^{19}$ Plasters were removed for radiological and functional testing and then reapplied.

The ROM was measured using a standard full circle goniometer. Flexion and extension were measured in triplicate and the mean was recorded to minimise intraobserver bias. Each measurement was expressed as a percentage of the unaffected side.
The mass grip strength was measured using a JAMAR hand dynamometer (Therapeutic Equipment Corporation, Clyton, New Jersey). In accordance with the guidelines for its use, ${ }^{28}$ the second grip handle was used for all patients. The mean of three successive trials was used for the injured and uninjured hands and recorded as percentages of the unaffected side, as recommended by the American Society of Hand Therapists. ${ }^{29}$ Each patient was tested at similar times of the day to minimise the effect of diurnal variation. Grip strengths were adjusted by $10 \%$ for the non-dominant hand. ${ }^{30}$ Pinch strength between the thumb and index finger was measured similarly using a B\&L Engineering Pinch Gauge (B\&L Engineering, Tustin, California).

Functional assessment was measured using a modified Green/O'Brien score ${ }^{31}$ which includes scores for pain, satisfaction, ROM and grip strength. These scores were added, with 90 to 100 points being excellent, 80 to 89 good, 65 to 79 fair and less than 65 poor.

The time to return to work and sport was recorded in weeks.

All patients attended at eight weeks. Four failed to attend at 12 weeks (one group 1, three group 2), three at 26 weeks (all group 1), and five at one year (two group 1, three group 2).

The groups were compared by chi-squared or MannWhitney $\mathrm{U}$ tests for categorised or quantitative factors respectively. Multiple ordinal logistic regression was used to test the effect of study group on time to return to work, adjusted for previous employment status. Intention-to-treat analyses were carried out using the 'last observation carried forward' method, in which missing outcomes at later times are replaced by those from the last time at which a valid observation was made.

\section{Results}

A total of 30 patients were randomised into each group. There were no significant differences between the groups in 
Table III. Mean (range) Green/O'Brien scores ${ }^{31}$ and percentage good and excellent results

\begin{tabular}{lcll}
\hline Review time (wks) & Operative & Non-operative & p-value \\
\hline 8 & $79(35$ to 100$)$ & $39(5$ to 70$)$ & $<0.001$ \\
Good/excellent (\%) & 52 & 0 & $<0.001$ \\
& & & \\
12 & $88(50$ to 100$)$ & $56(15$ to 100$)$ & $<0.001$ \\
Good/excellent (\%) & 68 & 15 & $<0.001$ \\
& & & \\
26 & $92(70$ to 100$)$ & $78(5$ to 100$)$ & 0.006 \\
Good/excellent (\%) & 81 & 56 & 0.055 \\
& & & \\
52 & $94(80$ to 100$)$ & $81(10$ to 100$)$ & 0.32 \\
Good/excellent (\%) & 100 & 88 & 0.025 \\
\hline * Mann-Whitney U test & & & \\
\hline
\end{tabular}

Table IV. Mean (range) times taken to return to normal activities of daily living $(A D L)$. One patient in each group did not return to sports at one year, the patient in the cast group had not returned to work either

\begin{tabular}{llcc}
\hline $\begin{array}{l}\text { Mean time to return } \\
\text { to ADL (wks) }\end{array}$ & Operative & Non-operative & p-value* \\
\hline Full sports & $6.4(2$ to 20$)$ & $15.5(6$ to 26$)$ & $<0.001$ \\
Full employment & $3.8(0$ to 12$)$ & $11.4(0$ to 36$)$ & $<0.001$ \\
Dressing & $0.6(0$ to 2$)$ & $1.0(0$ to 11$)$ & 0.72 \\
Washing & $0.6(0$ to 2$)$ & $1.0(0$ to 11$)$ & 0.72 \\
Shopping & $1.6(0$ to 10$)$ & $2.8(0$ to 13$)$ & 0.34 \\
Housework & $1.6(0$ to 10$)$ & $2.7(0$ to 10$)$ & 0.14 \\
\hline
\end{tabular}

* Mann-Whitney U test

any of the baseline characteristics (Table I) although the imbalance in employment status was appreciable.

Functional outcome. Although the patients in the operative group regained their grip and pinch strength as well as the ROM more quickly in the earlier stages of review, there was no significant difference between the groups at final followup (Table II). Patients in the operative group consistently scored better on the modified Green/O'Brien score until one year (Table III).

As Table IV shows, patients in the operative group had a quicker return to sport (mean 6.4 weeks (2 to 20)) and full employment (mean 3.8 weeks (0 to 12)) compared with those treated non-operatively (mean 15.5 weeks (6 to 26) and 11.4 weeks (0 to 36) respectively) but showed no differences in other functional tasks. The data in relation to return to work may be skewed as a result of the uneven distribution between the groups in physical demands of employment but the advantage to the operative group still remained significant (multiple ordinal logistic regression, $\mathrm{p}<0.001$ ) after adjusting for this.

Complications. In the operetive group, there were two cases with peri-operative problems, both caused by breakage of the cannulated screwdriver. One patient had symptoms
Table V. Radiological outcome for the two groups at each review period

\begin{tabular}{|c|c|c|c|}
\hline & Operative & Non-operative & p-value \\
\hline \multicolumn{4}{|l|}{ Displacement } \\
\hline Initial & 5 & 2 & $\mathrm{NS}^{*}$ \\
\hline 8 wks & 0 & 3 & NS \\
\hline 12 wks & 0 & 3 & NS \\
\hline 26 wks & 0 & 3 & NS \\
\hline 52 wks & 0 & 3 & NS \\
\hline \multicolumn{4}{|l|}{ Resorption } \\
\hline Initial & 0 & 0 & NS \\
\hline 8 wks & 0 & 8 & $0.02^{\dagger}$ \\
\hline 12 wks & 0 & 7 & NS \\
\hline 26 wks & 0 & 1 & NS \\
\hline 52 wks & 0 & 0 & NS \\
\hline Non/delayed union & 1 & 4 & NS \\
\hline Mean time to union (wks) & 9.2 (8 to 18 ) & 13.9 (8 to 36$)$ & $\begin{array}{l}<.001^{\ddagger} \\
\end{array}$ \\
\hline
\end{tabular}

from a screw protruding into the scaphotrapezial joint and was awaiting admission for its removal at final review. There were no infections and no cases of avascular necrosis (AVN). In the non-operative group two patients had radiological evidence of AVN. One had persistent pain at 52 weeks consistent with complex regional pain syndrome type 1 . Three patients had malunion of the fracture with residual dorsal intercalated segment instability deformity and one had symptomatic radioscaphoid osteoarthritis at final review.

Radiological outcome. Table V compares the radiological outcomes in the two groups. Of the outcomes shown, only resorption at eight weeks (chi-squared test, $\mathrm{p}=0.02$ ) and time to union (Mann-Whitney U test, $\mathrm{p}<0.001$ ) showed a significant difference between the groups. Although more patients in the operative group achieved union this was not quite significant (chi-squared test, $\mathrm{p}=0.15$ ).

\section{Discussion}

We have shown that percutaneous screw fixation has some advantages over cast immobilisation for the treatment of Herbert type B1 and B2 fractures of the waist of the scaphoid. There was a trend towards fewer nonunions in the patients treated with fixation but this did not reach statistical significance. The patients who were treated surgically returned to work a mean of seven weeks earlier and to sport nine weeks sooner than those treated non-operatively. They also had a more rapid return to function when measured objectively and using the Green/O'Brien score, which includes patient-rated outcome measures. Complication rates were low in both groups.

There have been four previous randomised controlled trials comparing internal fixation of fractures of the scaphoid 
Table VI. The results from randomised controlled trials of fixation versus cast immobilisation in fractures of the scaphoid. All differences are comparing operative with non-operative methods (NS, not significant; NR, not reported)

\begin{tabular}{|c|c|c|c|c|c|c|}
\hline & Number of cases & Union time & Nonunion & Return to work & Range of movement & Grip strength \\
\hline Adolfsson et $\mathrm{al}^{33}$ & 53 & NS & NS & NR & $p<0.02$ & NS \\
\hline Saedén et $a^{34}$ & 62 & NR & NS & $p=0.002$ & NS (12-year review) & NS (12-year review) \\
\hline Bond et $\mathrm{al}^{23}$ & 25 & $\begin{array}{l}4 \text { to } 5 \text { weeks early } \\
(p=0.0003)\end{array}$ & NS & $\begin{array}{l}7 \text { weeks early } \\
(p=0.0001)\end{array}$ & NS (2-year review) & NS (2-year review) \\
\hline Dias et $\mathrm{al}^{32}$ & 88 & & $p=0.001$ & NS & $p=0.001$ at 8 weeks & $\begin{array}{l}\mathrm{p}=0.006 \text { at } 12 \\
\text { weeks }\end{array}$ \\
\hline
\end{tabular}

with cast immobilisation, two using percutaneous methods and two using open fixation. ${ }^{23,32-34}$ All showed more rapid return of function in terms of movement and grip strength in the operative group (Table VI), which is confirmed in our study. Two studies showed a significantly faster return to work in the surgical group, ${ }^{23,34}$ similar to ours.

There seems to be an emerging message that early fixation of fractures of the scaphoid results in earlier union and a reduced rate of nonunion. In our study, early percutaneous fixation accelerated union by almost five weeks compared with cast management, despite the fact that the mean time to union might have been expected to be prolonged in the surgical group which contained more displaced fractures. This finding could be criticised because of the absence of blinding in the assessment of union. However, blinding is not possible in such a study because of the presence of the screw but this is mitigated by stringent criteria for the definition of union. The determination of time to union is limited by the frequency of follow-up and acquisition of radiographs. Ideally, these would have been taken weekly. However, because of practical limitations at each institute, it was decided that they would be taken only at designated follow-up visits.

Two other studies reported improvements in union. Dias et $\mathrm{al}^{32}$ found a significantly greater number of nonunions in their cast group while Bond et $\mathrm{al}^{23}$ noted accelerated union similar to ours in their operative group. The former study recruited the largest numbers of patients and used CT to diagnose nonunion.

Our use of the Green/O'Brien score consistently found better results in operatively-treated patients until after the six-month review. The only other study using a validated outcome score also found increased patient satisfaction but only at an early stage. ${ }^{32}$

In terms of cost effectiveness, Davis et $\mathrm{al}^{24}$ argue compellingly for the surgical treatment of nondisplaced fractures of the waist of the scaphoid. Their surgical model was open reduction and internal fixation. Presumably the cost of operative fixation would be even less in a percutaneous model, assuming less time is spent in the operating room and with a lower rate of complications.

Despite its limitations, our study confirms earlier time to union and quicker return to work and sport with percutaneous screw fixation of nondisplaced fractures of the waist of the scaphoid. We recommend that all active patients with a fracture of the waist of the scaphoid should be offered percutaneous internal fixation.

We would like to acknowledge the Scottish Orthopaedic Research Trust into Trauma (SORTIT) for their assistance in performing this study. We would also like to thank Dr R. Elton for his assistance with the statistical analysis.

No benefits in any form have been received or will be received from a commercial party related directly or indirectly to the subject of this article.

\section{References}

1. McQueen MM. Hand fractures and dislocations. In: Court-Brown CM, McQueen MM, Tornetta P, eds. Orthopaedic surgery essentials: trauma. Philadelphia: Lippincott, Williams and Wilkins, 2006:170-207.

2. Lindström G, Nyström Å. Natural history of scaphoid non-union, with special reference to "asymptomatic" cases. J Hand Surg [Br] 1992;17:697-700.

3. Cooney WP, Dobyns JH, Linscheid RL. Fractures of the scaphoid: a rational approach to management. Clin Orthop 1980;149:90-7.

4. Morgan DAF, Walters JW. A prospective study of 100 consecutive carpal scaphoid fractures. Aust NZ J Surg 1984;54:233-41.

5. Szabo RM, Manske D. Displaced fractures of the scaphoid. Clin Orthop 1988;230:30-8

6. Dabezies EJ, Mathews R, Faust DC. Injuries to the carpus: fractures of the scaphoid. Orthopedics 1982;5:1510-21.

7. Gellman H, Caputo FJ, Carter V, Aboulafia A, McKay M. Comparison of short and long thumb-spica casts for non-displaced fractures of the carpal scaphoid. J Bone Joint Surg [Am] 1989;71-A:354-7.

8. Amadio PC, Berquist TH, Smith DK, et al. Scaphoid malunion. J Hand Surg [Am] 1989;14:679-87.

9. Jiranek WA, Ruby LK, Millender LB, Bankoff MS, Newberg AH. Long-term results after Russe bone-grafting: the effect of malunion of the scaphoid. J Bone Joint Surg $[$ Am] 1992;74-A:1217-28.

10. Mack GR, Bosse MJ, Gelberman RH, Yu E. The natural history of scaphoid nonunion. J Bone Joint Surg [Am] 1984;66-A:504-9.

11. Ruby LK, Stinson J, Belsky MR. The natural history of scaphoid non-union: a review of fifty-five cases. J Bone Joint Surg [Am] 1985;67-A:428-32.

12. Düppe H, Johnell O, Lundborg G, Karlsson M, Redlund-Johnell I. Long-term results of fracture of the scaphoid: a follow-up study of more than thirty years. J Bone Joint Surg [Am] 1994;76-A:249-52.

13. Burgess RC. The effects of a simulated scaphoid malunion on wrist motion. $J$ Hand Surg [Am] 1987;12:774-6.

14. Barton NJ. Twenty questions about scaphoid fractures. J Hand Surg $[\mathrm{Br}]$ 1992:17:289-310

15. Clay NR, Dias JJ, Costigan PS, Gregg PJ, Barton NJ. Need the thumb be immobilised in scaphoid fractures: a randomised prospective trial. J Bone Joint Surg [Br] 1991;73-B:828-32.

16. O'Brien L, Herbert T. Internal fixation of acute scaphoid fractures: a new approach to treatment. Aust NZ J Surg 1985;55:387-9.

17. Skirven T, Trope J. Complications of immobilisation. Hand Clin 1994;10:53-61.

18. Herbert TJ, Fisher WE. Management of the fractured scaphoid using a new bone screw. J Bone Joint Surg [Br] 1984;66-B:114-23.

19. Wozasek GE, Moser KD. Percutaneous screw fixation for fractures of the scaphoid. J Bone Joint Surg [Br] 1991;73-B:138-42.

20. Rettig AC, Weidenbener EJ, Gloyeske R. Alternative management of midthird scaphoid fractures in the athlete. Am J Sports Med 1994;22:711-14.

21. Rettig AC, Kollias SC. Internal fixation of acute stable scaphoid fractures in the athlete. Am J Sports Med 1996;24:182-6. 
22. Haddad FS, Goddard NJ. Acute percutaneous scaphoid fixation: a pilot study. $J$ Bone Joint Surg [Br] 1998;80-B:95-9.

23. Bond CD, Shim AY, McBride MT, Dao KD. Percutaneous screw fixation or cast Immobilization for nondisplaced scaphoid fractures. J Bone Joint Surg [Am] 2001;83-A:483-8

24. Davis EN, Chung KC, Kotsis SV, Lau FH, Vijan S. A cost/utility analysis of open reduction and internal fixation versus cast immobilisation for acute nondisplaced mid-waist scaphoid fractures. Plastic \& Reconstructive Surgery 2006;117:1223-35.

25. Ziter FM. A modified view of the carpal navicular. Radiology 1973;108:706-7.

26. Daly K, Gill P, Magnussen PA, Simonis RB. Established nonunion of the scaphoid treated by volar wedge grafting and Herbert screw fixation. $J$ Bone Joint Surg [Br] 1996;78-B:530-4.

27. Rajagopalam BM, Squire DS, Samuels LO. Results of Herbert-screw fixation with bone-grafting for the treatment of nonunion of the scaphoid. J Bone Joint Surg [Am] 1999;81-A:48-52.
28. No authors listed. American Society for Surgery of the Hand. Clinical assessment recommendations. In: The hand: examination and diagnosis. Second ed. New York: Churchill Livingstone, 1983:106-7.

29. No authors listed. American Society of Hand Therapists. In: Garner NC, ed. Clinical assessment recommendations. The Society, 1981:6-8

30. Bechtol CO. Grip test: use of a dynamometer with adjustable handle spacing. J Bone Joint Surg [Am] 1954;36-A:820-4.

31. Cooney WP, Linscheid RL, Dobyns JH. Triangular fibrocartilage tears. J Hand Surg [Am] 1994;19:143-54.

32. Dias JJ, Wildin CJ, Bhowal B, Thompson JR. Should acute scaphoid fractures be fixed?: a randomised controlled trial. J Bone Joint Surg [Am] 2005;87-A:2160-8.

33. Adolfsson L, Lindau T, Arner M. Acutrak screw fixation versus cast immobilisation for undisplaced scaphoid wrist fractures. J Hand Surg [Br] 2001;26:192-5.

34. Saedén B, Törnkvist H, Ponzer S, Höglund M. Fracture of the carpal scaphoid: a prospective, randomised 12-year follow-up comparing operative and conservative treatment. J Bone Joint Surg [Br] 2001;83-B:230-4 